\title{
Doppler ultrasound and the silent ductus arteriosus
}

\author{
A B Houston, J P Gnanapragasam, M K Lim, W B Doig, E N Coleman
}

\begin{abstract}
A clinically undetectable, small ductus arteriosus was identified by Doppler ultrasonography in 21 individuals. Infants were excluded from the study and no patient had pulmonary hypertension. Persistence of the ductus arteriosus is likely to be more common than shown by less sensitive diagnostic methods. Some patients considered to have infective endocarditis with a normal heart may have a silent ductus arteriosus. Evidence of such an association would justify ligation or antibiotic cover as prophylactic measures.
\end{abstract}

The classic continuous murmur of ductus arteriosus is usually sufficient in itself to lead to surgical closure being undertaken. However, the murmur may be atypical in infancy or in the presence of pulmonary hypertension or a large shunt. ${ }^{1-3}$ The term "silent duct" was coined to describe the preterm infant with respiratory distress syndrome in whom the ductul murmur is not heard. ${ }^{4}$ Doppler ultrasonography has led to the recognition of a small ductus arteriosus with normal pulmonary artery pressure which cannot be identified clinically.

We report our experience in identifying such a "silent duct" in 21 patients examined clinically and by ultrasonography over a three year period.

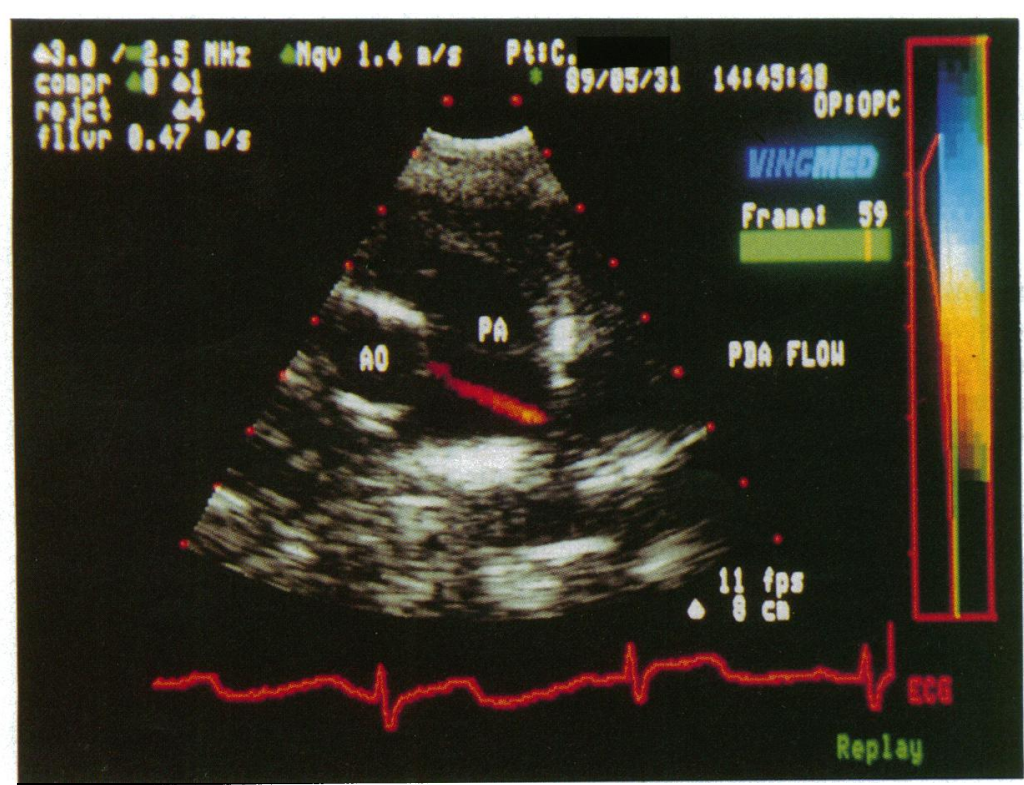

Figure Colour Doppler flow mapping image from a child with a silent ductus arteriosus showing flow from the aorta $(A o)$ into the pulmonary artery $(P A)$.

\section{Patients and methods}

Because of reported difficulties in duct recognition in infants ${ }^{3}$ the patients reported on were all more than 12 months old.

We considered that the description of "silent duct" was justified when there was:

(a) No continuous or crescendo systolic murmur during normal respiration or deep inspiration. (Patients with a murmur were included if it was typically innocent (including soft midsystolic murmurs in the pulmonary area) or if it was clearly due to another lesion but was so soft that it could not be conducted to the pulmonary area.)

(b) No evidence of pulmonary hypertension from clinical, electrocardiographic, and Doppler studies.

(c) A characteristic Doppler signal showing continuous flow with a relatively high velocity in diastole recognised by spectral Doppler and recognition of typical ductal flow by colour flow Doppler (when available).

Ultrasound studies were initially performed with an ATL imaging system and a stand alone Vingmed Alfred Doppler system interfaced to a Doptek spectrum analyser. Later we used a Vingmed CFM 700 imaging and colour flow system.

The routine ultrasound study included echocardiographic imaging of systemic and pulmonary veins, intracardiac anatomy, and great artery anatomy; and spectral Doppler measurement of flow velocities through all four valves and the ascending and descending aorta-with a similar colour Doppler flow mapping study to search for any left to right shunt or other abnormality. The ductal spectral signal was recorded by the stand alone or imaging transducer with the transducer in the suprasternal notch or upper left sternal edge. When we used colour Doppler flow mapping, flow was best recorded from a modified short axis view of the great arteries similar to that used to image a duct ${ }^{5}$ (fig 1). In some it was better seen from the suprasternal notch with the image showing the aorta in cross section and both the pulmonary artery branches and their confluence.

When Doppler echocardiography showed a ductus arteriosus not suspected on clinical examination the patient was re-examined by two cardiologists; if a systolic crescendo or continuous murmur which might be considered of ductal origin was then heard the patient was excluded from the group.

During the same period a total of 7345 ultrasound studies were performed. Table 1 
Table 1 Age and sex distribution of 21 patients with a silent ductus arteriosus

\begin{tabular}{lllll}
\hline \multirow{2}{*}{$\begin{array}{l}\text { Age group } \\
\text { (yr) }\end{array}$} & \multicolumn{2}{l}{ Number of cases } & \multicolumn{2}{l}{$\%$ in random } \\
\cline { 2 - 4 } & Males & Females & Total & sample of 360 \\
\hline $1-5$ & 4 & 4 & 8 & 49 \\
$6-10$ & 1 & 6 & 7 & 17 \\
$11-15$ & 3 & 2 & 5 & 7 \\
Over 15 & - & 1 & 1 & 4 \\
\hline
\end{tabular}

shows the age distribution from a random sample of 360 .

Although most children undergoing echocardiography had a murmur there were some with no clinical cardiovascular abnormality, such as patients with Kawasaki disease, Marfan's syndrome, neurological abnormalities associated with cardiac abnormalities, and those on anthracycline treatment in whom left ventricular function was being monitored. Exact numbers of these patients were not recorded. Some patients with innocent murmurs were studied as part of another study. In a sample of 720 consecutive ultrasound studies no cardiac abnormality was detected in $36 \%$.

\section{Results}

On the basis of the above criteria we identified clinically silent ducts in 20 children over the age of 12 months who underwent echocardiography during a three year period and in one adult who had an ultrasound scan for demonstration purposes. Six patients had no murmur, two had soft murmurs of other defects, and the remaining 13 had innocent murmurs (table 2). Two had previously undergone surgical ligation of the ductus arteriosus. The distribution of the children was similar in the three age groups of 1-5 years, 6-10 years, and 11-15 years though more younger children had been studied (table 1). In no patient was the duct visible on cross sectional imaging and in all the left ventricular size and function were normal.

Silent ducts were also found in several patients with other defects and relatively loud murmurs but these were not included because of the stringent criteria used for the definition of the "silent duct".

No murmur (6)

Kawasaki disease (1)

Marfan's syndrome (1)

Tuberous sclerosis (1)

Referred with an

innocent murmur (1)

Five years after ligation of duct (1)

Demonstration scan in a 25 year old (1)

Innocent murmur (13)

Soft basal mid-systolic murmur (7)

Still's murmur (6)

Soft murmur of other

defect (2)
Small muscular

ventricular septal

ventricular septal
defect with a soft

pansystolic murmur a

pansystolic murmur at

the lower

Mitral valve prolapse

with a soft pansystolic murmur at the apex 13 years after ligation of duct (1)

Numbers of patients are indicated in parentheses. tion. Most cases of an atypical murmur were associated with a very large ductal flow or pulmonary hypertension. ${ }^{12}$ Rowe described a group of patients who presented with nonspecific murmurs, clinically not of ductal origin, and in whom invasive investigations showed a trivial duct ${ }^{10}$; these patients resemble the group that we studied.

We describe the identification of a ductus arteriosus by Doppler echocardiography in patients who were later reassessed by experienced cardiologists with the possibility of the diagnosis in mind; they could find no clinical evidence of a ductus arteriosus. The ultrasound detection of a silent ductus arteriosus is simple and this diagnosis will become increasingly common as sensitive Doppler echocardiographic techniques become more widely used. Before the introduction of Doppler techniques a ductus arteriosus would not have been recognised in these patients. Our patients came from a group who were referred for ultrasound studies for various reasons (table 2). Thirteen had been referred with an innocent murmur and in six no murmur was audible. In addition ductal flow which could not be detected clinically was demonstrated in patients with other defects who were excluded because the murmur of the other lesion (such as aortic stenosis, coarctation of the aorta, or ventricular septal defect) was loud at the upper left sternal edge. The findings indicate that as many as $0.5 \%$ in those presenting with innocent murmurs may have a ductus arteriosus. Because our patients are from a selected group we cannot estimate the incidence of a ductus arteriosus in the general population. It is likely to be higher than that estimated by previous diagnostic methods $(0.065 \%){ }^{11}$

Early reports of a high incidence of infective endocarditis in those with a ductus arteriosus $^{712}$ led to the view that closure is the appropriate treatment. Should this recommendation apply to a ductus arteriosus that is so small that it evades clinical detection? The patient is certainly not at risk from pulmonary vascular disease or cardiac failure and the only possibility that needs to be considered is infective endocarditis. If the incidence of infective endocarditis in those with a clinically apparent duct $(40 \%)^{712}$ was found in those with a silent duct it seems likely that the association would have been recognised before now. However, it is possible that patients considered to have infective endocarditis in a normal heart may have a minor abnormality such as a tiny duct. At present we do not recommend either closure or antibiotic prophylaxis; but further experience may modify our policy. We explain the nature of the lesion to patients or parents and stop routine follow up examinations. We maintain a register of their names so that if opinion changes they can be recalled.

Two patients in our group had previously undergone surgical ligation of a duct. In one patient no murmur was audible and in the other only the murmur of mitral valve prolapse was present. However, Doppler ultrasonography identified a tiny residual ductal flow in both There have recently been reports of the finding of tiny, clinically inaudible residual leaks detectable only by detailed Doppler ultrasound in some patients who had undergone transcatheter umbrella occlusion of a ductus arteriosus. ${ }^{1314}$ But it should be borne in mind 
that clinically undetectable trivial residual flow may occur after surgical ligation as shown in two of our patients.

Doppler ultrasonography can identify previously unrecognised features of the pattern of blood flow in the heart and vessels. Some of these may be the apparently normal finding of physiological valve regurgitation ${ }^{15}$ and others a minor abnormality such as the silent ductus arteriosus. Do patients with a silent ductus arteriosus require prophylaxis against infective endocarditis? Doppler ultrasound examination of patients with infective endocarditis but without clinically recognisable antecedent heart disease and long term prospective studies may establish the place of antibiotic prophylaxis.

We thank Mr E P Murtagh, Mr S Lilley, Mr R A Fraser, and Mr $G$ Olafsson who made the ultrasound diagnosis in many of the subjects.

JPG is in receipt of a grant from the Equipment Evaluation Committee of the Scottish Home and Health Department.

1 Adams FH, Diehl A, Jorgens J, Veasy LC. Catheter findings in typical and atypical patent ductus arteriosus and in 1952;40:49-59.

2 Krovetz LJ, Warden HE. Patent ductus arteriosus. An analysis of 515 surgically proved cases. Dis Chest 1962;42:46-57.

3 Rowe RD, Lowe JB. Auscultation in the diagnosis of persistent ductus arteriosus in infancy. NZ Med $J$ 1964;63:195-9.

4 McGrath RL, McGuiness GA, Way GL, Wolfe RR, Nora JJ, Simmons MA. The silent ductus arteriosus. J Pediatr 1978;93:110-3.

5 Smallhorn JF, Huhta JC, Anderson RH, Macartney FJ. Suprasternal cross-sectional echocardiography in assessment of patent ductus arteriosus. Br Heart $J$ 1982;48: ment of

6 Marquis RM. The continuous murmur of persistence of the ductus arteriosus-an historical review. Eur Heart $J$ ductus arterios
$1980 ; 1: 465-78$

7 Bullock LT, Jones JC, Dolley FS. The diagnosis and the effects of ligation of the patent ductus arteriosus. J Pediatr 1939;1 5:786-801.

8 Crafoord C, Mannheimer E, Wiklund T. The diagnosis and the treatment of patent ductus arteriosus in connection with 20 operated cases. Acta Chir Scand 1944;91:97-131.

9 Levine $S$. The diagnosis of patent ductus arteriosus and the indications for operation. Acta Med Scand 1947;128 (suppl 196): 145-59.

10 Rowe RD. Patent ductus arteriosus. In: Keith JD, Rowe $\mathrm{RD}$, Vlad $\mathrm{P}$, eds. Heart disease in infancy and childhood. New York: Macmillan 1978;427.

11 Dickinson DF, Arnold R, Wilkinson JL. Congenital heart disease among 160480 liveborn children in Liverpool 1960 to 1969 . Implications for surgical treatment. $\mathrm{Br}$ 1960 to 1969 . Implicatio

12 Keys A, Shapiro MJ. Patency of the ductus arteriosus in Keys A, Shapiro MJ. Patency of the
adults. Am Heart J 1943;25:158-86.

13 Mullins CE. Pediatric and congenital therapeutic cardiac catheterization. Circulation 1989;79:1153-9.

14 Rashkind WJ, Mullins CE, Hellenbrand WE, Tait MA. Non surgical closure of patent ductus arteriosus: clinical application of the Rashkind PDA occluder system. Circulation 1987;75:583-92.

15 Yoshida K, Yoshikawa J, Shakudo M, et al. Colour Doppler evaluation of valvular regurgitation in normal subjects. Circulation 1988;78:840-7. 